Artikel Asli

Indikator Penilaian dari Dukungan Nenek berkorelasi paling kuat terhadap Praktik Pemberian ASI non Eksklusif pada Ibu Primipara Muda yang Bekerja

\title{
Assessment Indicator from Grandmothers' Support Was the Strongest Correlation to Non-Exclusive Breastfeeding Practice in Young Primiparous Working Mothers
}

Muladefi Choiriyah ${ }^{1 *}$, Ziadah Nikmatur Rizqiyah ${ }^{2}$, Setyoadi $^{3}$, Ayut Merdikawati ${ }^{4}$

1,2,3,4Jurusan Keperawatan, Fakultas Kedokteran, Universitas Brawijaya

*Korespondensi penulis:

Muladefi Choiriyah

Jurusan Keperawatan, Fakultas Kedokteran, Universitas Brawijaya

Puncak Dieng Eksklusif, Kunci, Kalisongo, Kec. Dau, Malang, Jawa Timur 65151

Email:defi.fk@ub.ac.id

\begin{tabular}{ll}
\hline Info Artikel & ABSTRAK \\
\cline { 2 - 3 } Riwayat Artikel: & Ibu primipara akan mengalami berbagai masalah menyusui karena \\
Dikirim 22 Februari 2021 & merupakan pengalaman pertama, terutama bagi ibu yang bekerja. Oleh \\
Direvisi 8 Maret 2021 & karena itu, mereka perlu mendapat dukungan dari keluarganya, terutama \\
Diterima 8 Maret 2021 & dari nenek. Penelitian ini bertujuan untuk menganalisis hubungan dukungan \\
& nenek dengan pemberian ASI Eksklusif pada ibu primipara bekerja. \\
& Penelitian yang dilakukan di wilayah kerja Puskesmas Arjowinangun Malang- \\
\hline Kata Kunci: & Jawa Timur ini, menggunakan pendekatan studi potong lintang. \\
Dukungan Nenek & Pengumpulan data menggunakan purposive sampling dengan kuesioner. \\
ASI Eksklusif & Seratus tiga puluh dua responden setuju untuk berpartisipasi dalam \\
Primipara & penelitian ini. Hasil penelitian menunjukkan bahwa sebagian besar ibu yang \\
Ibu Bekerja & memilih menyusui non-eksklusif mendapat dukungan yang kurang. Ada \\
& hubungan yang signifikan dan berkorelasi sangat kuat antara dukungan \\
& nenek dengan perilaku menyusui (p-value = 0.000; r $=0.831)$ yang berarti \\
& semakin baik dukungan nenek maka semakin baik perilaku ASI eksklusif ibu \\
& bekerja primipara. Semua indikator dukungan memiliki kategori dukungan \\
& cukup. Indikator dukungan penilaian memiliki korelasi tertinggi dengan \\
& menyusui non-eksklusif (r = 0.649). Kesimpulannya, dukungan nenek \\
& memiliki peran yang signifikan dalam keberhasilan menyusui ASI Eksklusif \\
& bagi ibu bekerja, sehingga bantuan ASI oleh tenaga kesehatan harus \\
& difokuskan pada ibu dan keluarga terutama nenek.
\end{tabular}

\begin{tabular}{|c|c|}
\hline & ABSTRACT \\
\hline $\begin{array}{l}\text { Keywords: } \\
\text { Grandmother's Support } \\
\text { Exclusive Breastfeeding } \\
\text { Primiparous } \\
\text { Working Mother }\end{array}$ & $\begin{array}{l}\text { Primiparous mothers will experience various breastfeeding problems because it } \\
\text { is the first experience, especially for working mothers. Therefore, they need to } \\
\text { get support from their families, mainly from grandmothers. This study aims to } \\
\text { analyze the correlation between the grandmother's support and exclusive } \\
\text { breastfeeding for primiparous mothers working. This study, conducted in the } \\
\text { Arjowinangun Community Health Center coverage area, Malang, used a cross- } \\
\text { sectional study approach. The data collection used purposive sampling and } \\
\text { questionnaires. One hundred thirty-two respondents had agreed to participate } \\
\text { in this study. The results show that most mothers who choose non-exclusive } \\
\text { breastfeeding had received insufficient support. There was a significant and } \\
\text { strong correlation between grandmother's support and breastfeeding behavior } \\
\text { (p-value = 0.000; } r=0.831 \text { ), which means that the better the grandmother's } \\
\text { support, the better exclusive breastfeeding behavior primiparous working } \\
\text { mothers. All the support indicators were sufficient categories. The assessment } \\
\text { support was the highest correlation to non-exclusive breastfeeding (r = 0.649). } \\
\text { The conclusion is grandmother's support has a significant role in the success of } \\
\text { exclusive breastfeeding for working mothers, so breastfeeding assistance by } \\
\text { health workers should focus on mothers and families, especially grandmothers. }\end{array}$ \\
\hline
\end{tabular}




\section{Pendahuluan}

Indonesia belum mencapai target pemberian ASI eksklusif untuk bayi berusia 0 hingga 6 bulan, yaitu 54\%, padahal target nasional $80 \%$ untuk ASI eksklusif. Persentase pemberian ASI eksklusif di provinsi Jawa Timur masih mencapai 48,1\%. Menurut Profil Kesehatan Kota Malang 2016, ASI eksklusif di Kota Malang sebesar 75,27\% (Dinkes Malang, 2016). Rendahnya cakupan ASI eksklusif menunjukkan bahwa masyarakat tidak sepenuhnya menyadari pentingnya menyusui eksklusif.

Dua faktor utama yang dapat mempengaruhi ibu untuk memberikan ASI eksklusif adalah internal dan eksternal. Faktor internal misalnya, tingkat pengetahuan, persepsi, dan kondisi kesehatan ibu. Sementara itu, faktor eksternal berasal dari luar ibu atau dari lingkungan ibu. Faktor tersebut dapat mempengaruhi keputusan ibu untuk memberikan ASI eksklusif atau tidak; misalnya, ibu mendapat dukungan keluarga, dukungan kesehatan, adanya promosi susu formula di lingkungannya (McQueen, dkk., 2015).

Salah satu faktor yang dapat sangat mempengaruhi persepsi dan keputusan seorang ibu untuk memberikan ASI eksklusif kepada bayinya adalah dukungan keluarga. Ibu membutuhkan dukungan keluarga selama menyusui. Studi sebelumnya menunjukkan korelasi antara dukungan keluarga dan perilaku menyusui eksklusif (Oktalina, dkk., 2015). Dukungan nenek adalah salah satu dukungan paling substansial dari anggota keluarga karena mereka mempertimbangkan untuk merawat bayi dan menyusui. Nenek memiliki kapasitas besar untuk mempengaruhi dan pengambilan keputusan tentang menyusui eksklusif, dan temuan ini menunjukkan bahwa peran nenek menjadi penting (Negin, dkk., 2016; Scelza dan Hinde, 2019).

Ibu membutuhkan dukungan nenek saat menyusui bayi mereka, terutama untuk ibu primipara, karena menjadi ibu untuk pertama kalinya tidaklah mudah. Ibu primipara akan mengalami beberapa kesulitan dalam merawat bayi dan menyusui. Orang tua adalah orang-orang yang dapat dipercaya dan diandalkan di masa-masa ini. Ibu meniru pengalaman dan pengetahuan orang tua mereka tentang cara menyusui dan merawat bayi, terutama orang tua atau nenek perempuan yang sudah memiliki pengalaman dengan ini. Sehingga, dukungan dari nenek diperlukan untuk sukses menyusui eksklusif (Zhu, dkk., 2016).

Faktor lain untuk cakupan rendahnya menyusui eksklusif adalah ibu yang bekerja. Upaya untuk memberikan ASI eksklusif sering mengalami hambatan ketika ibu harus kembali bekerja (Dahlan, dkk., 2013; Chang, dkk., 2019). Pemerintah juga telah secara jelas mendukung pemberian ASI eksklusif bagi ibu yang bekerja dalam beberapa peraturan, seperti menyediakan ruang menyusui di tempat kerja. Namun, cakupan ASI eksklusif tetap rendah. Sementara ibu itu bekerja dan bayi tidak memberikan ASI perah, atau ibu dan anggota keluarga lainnya berpikir bahwa ASI ibu tidak mencukupi untuk bayi. Nenek cenderung memberikan makanan/minuman tambahan kepada bayi. Studi sebelumnya menunjukkan bahwa 69\% nenek telah menawarkan teh dan air kepada cucu mereka (Ferreira, dkk., 2018).

Menurut data primer Puskesmas Arjowinangun-Malang, Jawa Timur pada 2018, cakupan ASI eksklusif Arjowinangun masih rendah karena ada banyak ibu pekerja. Di Arjowinangun, beberapa pabrik dan pasar besar menyerap banyak tenaga kerja dari ibuibu, termasuk ibu-ibu yang masih menyusui. Ibu yang bekerja memilih untuk meninggalkan bayi mereka bersama nenek mereka sambil merawat mereka.

Sebuah studi tentang dukungan keluarga atau nenek dalam menyusui dilakukan oleh para peneliti di seluruh dunia bertahun-tahun yang lalu. Namun, kajian pada ibu-ibu muda primipara yang sedang bekerja masih kurang, khususnya di Indonesia. Oleh karena itu, tujuan penelitian ini untuk menganalisis korelasi antara dukungan nenek dan pemberian ASI eksklusif untuk ibu primipara yang bekerja.

\section{Metode}

Desain penelitian ini kuantitatif, dengan pendekatan cross sectional study. 
Penelitian ini telah dilakukan di Puskesmas Arjowinangun, Kota Malang, yang meliputi empat kelurahan, yaitu Mergosono, Tlogowaru, Bumiayu dan Arjowinangun pada Desember 2018-Februari 2019. Dalam penelitian ini, kriteria inklusi adalah ibu primipara yang bekerja dan menitipkan bayi mereka kepada nenek bayi saat ibu bekerja (selama periode ASI eksklusif). Pengumpulan data menggunakan purposive sampling dengan kuesioner. Peneliti memodifikasi dukungan keluarga dan kuesioner menyusui eksklusif dengan mengadopsi penelitian (Ratnasari, dkk., 2017). Kuesioner dukungan keluarga diisi oleh nenek yang terdiri dari 20 pertanyaan: Dukungan Informasi, Dukungan Penilaian, Dukungan Instrumental, dan Dukungan Emosional. Pertanyaan dengan jawaban ya memiliki nilai 1 sementara bukan nilai 0 . Kemudian hasilnya ditafsirkan menjadi tiga kategori, yaitu dukungan yang baik, cukup, dan kurang. Dukungan baik jika skor 14-20, dukungan cukup 7-13, dan dukungan kurang jika skor $<7$.

Sementara itu, kuesioner menyusui eksklusif diisi oleh ibu untuk menganalisis perilaku menyusui. Analisis data menggunakan Spearman-rank test. Penelitian ini telah mendapat persetujuan etis dari Komite Etik dan Penelitian Kesehatan Fakultas Kedokteran Universitas Brawijaya No. 63/EC/KEPK/03/2018. Seratus tiga puluh dua responden terdiri dari 66 ibu dan 66 nenek dalam penelitian ini, telah menyetujui informed-consent yang diinformasikan sebelumnya.

\section{Hasil dan Pembahasan}

\section{Karakteristik Demografis}

Enam puluh enam ibu berpartisipasi dalam penelitian ini. Karakteristik ibu termasuk usia, Suku, pendidikan, pekerjaan, pendapatan, informasi menyusui eksklusif, masalah selama menyusui, tinggal bersama keluarga besar, dan ketersediaan ruang menyusui di tempat kerja, seperti yang disajikan dalam Tabel 1.

\begin{tabular}{|c|c|c|}
\hline Karakteristik & $\mathbf{N}$ & $\%$ \\
\hline \multicolumn{3}{|l|}{ Usia } \\
\hline - $17-25$ tahun & 32 & 48,5 \\
\hline$-26-35$ tahun & 34 & 51,5 \\
\hline \multicolumn{3}{|l|}{ Suku } \\
\hline - Jawa & 61 & 92,4 \\
\hline - Madura & 4 & 6,1 \\
\hline - Sunda & 1 & 1,5 \\
\hline \multicolumn{3}{|l|}{ Pendidikan } \\
\hline$-\quad S D$ & 9 & 13,6 \\
\hline - SMP & 15 & 22,7 \\
\hline - SMA & 34 & 51,5 \\
\hline - Diploma & 6 & 9,1 \\
\hline - Sarjana & 2 & 3,0 \\
\hline \multicolumn{3}{|l|}{ Pekerjaan } \\
\hline - $\quad$ PNS & 3 & 4,5 \\
\hline - Wiraswasta & 22 & 33,3 \\
\hline - $\quad$ Buruh & 30 & 45,5 \\
\hline - Lainnya & 11 & 16,7 \\
\hline \multicolumn{3}{|l|}{ Penghasilan } \\
\hline - $\quad<\mathrm{Rp}, 2,500,000$ & 47 & 71,2 \\
\hline$-\quad \geq \mathrm{RP}, 2,500,000$ & 19 & 28,8 \\
\hline
\end{tabular}

Tabel 2. Karakteristik Nenek $(n=66)$

\begin{tabular}{lcc}
\hline Karakteristik & N & $\mathbf{\%}$ \\
\hline Usia, tahun & & \\
- 36 - 45 & 13 & 19,7 \\
- 46 - 55 & 33 & 50,0 \\
- 56 - 65 & 20 & 30,3 \\
Suku & & \\
- Jawa & 58 & 87,9 \\
- Madura & 7 & 10,6 \\
- Sunda & 1 & 1,5 \\
Pendidikan & & \\
- SD & 30 & 45,5 \\
- SMP & 15 & 22,7 \\
- SMA & 12 & 18,2 \\
- Diploma & 1 & 1,5 \\
- Tidak Sekolah & 8 & 12,1 \\
Menerima Informasi & ASI & \\
Eksklusif & 42 & 63,6 \\
- Pernah & 24 & 36,4 \\
- Belum & & \\
\hline
\end{tabular}

Tabel 1 menunjukkan bahwa ibu berusia 26-35 tahun, Suku Jawa, pendidikan terakhir SMA, bekerja sebagai buruh, pendapatan kurang dari Rp. 2.500.000. Enam puluh enam nenek berpartisipasi dalam penelitian ini. Karakteristik nenek termasuk usia, suku, pendidikan, dan informasi menyusui eksklusif, seperti yang disajikan dalam Tabel 2. Tabel 2 menunjukkan bahwa sebagian besar nenek berusia 46-55 tahun, 
Suku Jawa, berpendidikan terakhir SD, dan telah menerima informasi tentang ASI eksklusif.

Tabel 3. Informasi Menyusui pada Ibu

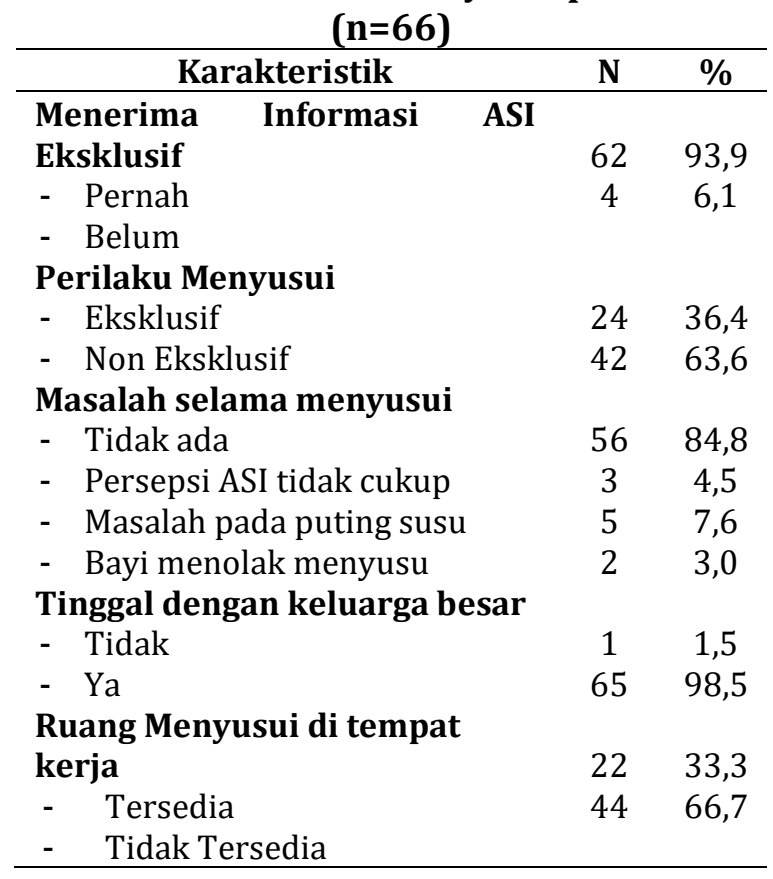

TabeL 4. Korelasi antara Dukungan Nenek dan Perilaku Menyusui pada ibu Bekerja

\begin{tabular}{lcccc}
\multirow{2}{*}{$\begin{array}{l}\text { Dukungan } \\
\text { Nenek }\end{array}$} & \multicolumn{3}{c}{ Perilaku Menyusui } \\
\cline { 2 - 5 } & \multicolumn{2}{c}{ NEBF } & \multicolumn{2}{c}{ EBF } \\
(N, \%) & \multicolumn{2}{c}{ (N, \%) } \\
\hline Usia & & & & \\
- 36-45 tahun & 8 & $(12,1)$ & 5 & $(7,6)$ \\
- 46-55 tahun & 21 & $(31,8)$ & 12 & $(18,2)$ \\
- 56-65 tahun & 13 & $(19,7)$ & 7 & $(10,6)$ \\
Pendidikan & & & & \\
- SD & 21 & $(31,8)$ & 9 & $(13,6)$ \\
- SMP & 8 & $(12,1)$ & 7 & $(10,6)$ \\
- SMA & 8 & $(12,1)$ & 4 & $(6,1)$ \\
- Diploma & 1 & $(1,5)$ & 0 & $(0)$ \\
- Tidak & 4 & $(6,1)$ & 4 & $(6,1)$ \\
$\quad$ Sekolah & & & & \\
Menerima & & & & \\
Informasi ASI & 25 & $(37,9)$ & 17 & $(25,8)$ \\
Eksklusif & 17 & $(25,8)$ & 7 & $(10,6)$ \\
- Pernah & & & & \\
- Belum & & & & \\
Dukungan & & & & \\
Nenek & & & & \\
- Kurang & 6 & $(9,1)$ & 0 & $(0)$ \\
- Cukup & 33 & $(50)$ & 1 & $(1,5)$ \\
- Baik & 3 & $(4,5)$ & 23 & $(34,8)$ \\
\hline
\end{tabular}

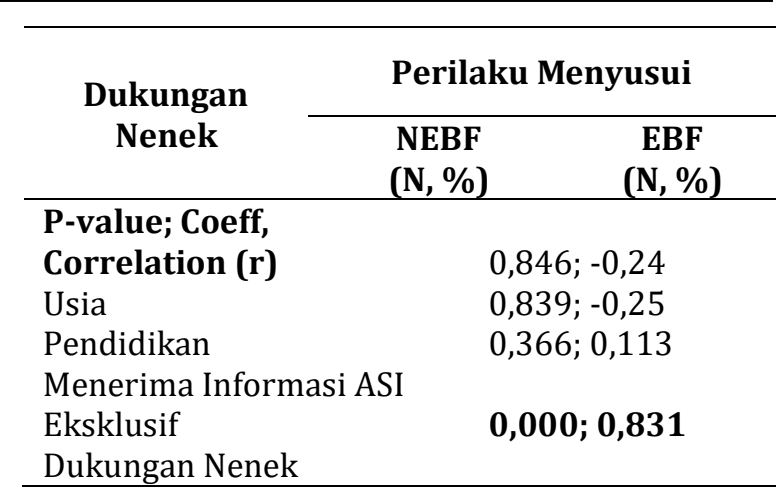

Tabel 5. Indikator Dukungan Nenek

\begin{tabular}{lcc}
\hline Indikator & \multicolumn{2}{c}{ Menyusui } \\
\cline { 2 - 3 } & NEB (N, \%) & EB (N, \%) \\
\hline Instrumental & $8(12,1)$ & $0(0)$ \\
Kurang & $21(31,8)$ & $4(6,1)$ \\
Cukup & $13(19,7)$ & $20(30,3)$ \\
Informasi & & \\
Kurang & $10(15,2)$ & $1(1,5)$ \\
Cukup & $29(43,9)$ & $5(7,6)$ \\
Baik & $3(4,5)$ & $18(27,3)$ \\
Penilaian & & \\
Kurang & $14(21,2)$ & $1(1,5)$ \\
Cukup & $25(37,9)$ & $5(7,6)$ \\
Baik & $3(4,5)$ & $18(27,3)$ \\
Emosional & & \\
Kurang & $3(4,5)$ & $0(0)$ \\
Cukup & $9(13,6)$ & $1(1,5)$ \\
Baik & $7(10,6)$ & $3(4,5)$ \\
\hline
\end{tabular}

P-value; Coeff,

Correlation (r)

Instrumental $\quad \mathbf{0 , 0 0 0 ; 0 , 5 1 2}$

Informasi $\quad \mathbf{0 , 0 0 0 ; 0 , 6 4 1}$

Penilaian $\quad 0,000 ; 0,649$

Emosional $\quad \mathbf{0 , 0 1 1 ; 0 , 3 1 3}$

Tabel 3 menunjukkan bahwa sebagian besar ibu telah menerima informasi tentang pemberian ASI eksklusif, memberikan ASI non eksklusif, tidak ada masalah dalam menyusui, tinggal dengan keluarga besar dan tidak memiliki ruang menyusui di tempat kerja. Korelasi antara dukungan nenek dan perilaku menyusui disajikan dalam Tabel 4. Tabel 4 menjelaskan bahwa sebagian besar responden ibu, yang memilih menyusui non-eksklusif, memiliki: ibu (nenek bayi) yang berusia 46-55 tahun, berpendidikan SD, sudah pernah menerima informasi tentang ASI ekslusif, dan memberikan dukungan yang baik kepada responden. 


\section{Dukungan Nenek untuk ASI Eksklusif}

Menyusui dikelompokkan menjadi ASI eksklusif/exclusive Breastfeeding (EBF) dan menyusui non-eksklusif/non-exclusive Breastfeeding (NEBF). Terdapat korelasi yang signifikan antara dukungan nenek dan menyusui eksklusif dengan nilai p-value 0.000 dan koefisien korelasi yang rendah 0.831 dan bernilai positif, yang berarti bahwa semakin baik dukungan nenek, perilaku menyusui eksklusif ibu pekerja primipara yang lebih baik. Peneliti juga menganalisis dukungan nenek berdasarkan empat indikator dukungan: instrumental, informasi, penilaian, emosional, dan, seperti yang disajikan dalam tabel 5. Tabel 5 menunjukkan bahwa semua indikator dukungan nenek berada dalam kategori cukup. Indikator penilaian memiliki korelasi tertinggi terhadap perilaku menyusui $(r=0,649)$ daripada yang lain.

Dukungan nenek yang kurang optimal cenderung membuat ibu primipara yang bekerja tidak memberikan ASI eksklusif. Penelitian sebelumnya menunjukkan bahwa kurangnya dukungan keluarga, terutama dari nenek, menyebabkan singkatnya durasi pemberian ASI eksklusif (Susiloretni, dkk., 2015; Trisnawati \& Widyastutik, 2018). Ibu yang keluarganya mendukung pemberian ASI eksklusif 3,5 kali lebih banyak menyusui eksklusif daripada mereka yang tidak mendukung (Ramadhani, 2017). Nenek memiliki peran penting dalam keberhasilan atau kegagalan menyusui eksklusif (Negin, dkk., 2016).

Pengetahuan nenek yang benar diterjemahkan ke dalam pemahaman ibu yang tepat dan, oleh karena itu, praktik pemberian nutrisi bayi menjadi optimal (Karmacharya, dkk., 2017). Penelitian sebelumnya menggambarkan bahwa untuk memberdayakan perempuan untuk menyusui eksklusif secara efektif; anggota keluarga kunci, harus dididik program pendidikan menyusui menggunakan teknik pengajaran yang praktis dan visual (Kohan, dkk., 2019; Ke dkk, 2018). Program edukasi kesehatan dapat mempengaruhi pengetahuan ibu tentang ASI eksklusif (Suryaningsih, 2013).

Kegagalan pemberian ASI eksklusif dipengaruhi oleh banyak faktor dari ibu atau keluarga. Salah satu faktor yang mempengaruhi dukungan ASI eksklusif adalah pendidikan. Menurut hasil penelitian ini, bahwa sebagian besar pendidikan terakhir nenek adalah sekolah dasar. Faktor pendidikan mempengaruhi penyediaan dukungan informasi. Dukungan keluarga berkorelasi dengan keputusan ibu primipara untuk memberikan ASI eksklusif atau tidak untuk bayi mereka. Penelitian ini menyatakan bahwa nenek memberikan dukungan informasi yang tidak memadai, meskipun mereka telah menerima informasi ASI eksklusif. Dukungan informasi ini dapat berupa menginformasikan makna dan manfaat ASI eksklusif serta cara memberikan ASI eksklusif saat ibu bekerja melalui ASI yang diekspresikan.

Dukungan keluarga dan tingkat pendidikan ayah yang tinggi sangat penting dalam memungkinkan ibu yang bekerja untuk berlatih menyusui eksklusif (Ratnasari, dkk., 2017). Ibu akan memiliki peluang 16 kali lebih besar untuk menyusui secara eksklusif jika mereka mendapatkan dukungan informasi yang baik daripada mereka yang berpenghasilan lebih sedikit (Rahmawati, 2016). Dukungan informasi juga berdampak pada dukungan instrumental yang diberikan; jika informasi memadai, maka tindakan juga akan berguna dalam perilaku menyusui eksklusif.

Oleh karena itu, bantuan dalam bentuk pelayanan/pemenuhan kebutuhan (instrumental) juga berkorelasi dengan pemberian ASI eksklusif terhadap ibu primipara yang bekerja. Pengetahuan menyusui akan memengaruhi perilaku seseorang, termasuk dukungan instrumental. Dukungan instrumental yang diberikan kepada ibu menyusui dapat berupa penyediaan makanan bergizi, bagi ibu menyusuinya yang kurang optimal. Hasil penelitian juga menunjukkan bahwa responden memberikan dukungan instrumental yang cukup.

Dukungan instrumental menjadi kurang optimal karena kurangnya informasi, perilaku kurang tepat, dan faktor status ekonomi. Hasil penelitian ini menjelaskan pendapatan keluarga di bawah Upah 
Minimum Regional tahun 2018. Jadi, ibu membantu meningkatkan status ekonomi keluarga dengan bekerja, meskipun mereka sedang menyusui. Penelitian sebelumnya menunjukkan bahwa ibu yang bekerja cenderung tidak memberikan ASI eksklusif (Dahlan, dkk., 2013).

Pengetahuan menyusui berhubungan dan berdampak dalam memberikan dukungan penilaian. Responden dengan pengetahuan rendah akan cenderung memiliki sikap negatif. Hasil penelitian ini, bahwa sebagian besar nenek memberikan dukungan yang cukup untuk indikator penilaian, hal tersebut dapat dikarenakan nenek sudah pernah mendapatkan informasi ASI eksklusif sebelumnya. Dukungan penilaian tersebut merupakan bentuk bimbingan dalam meningkatkan harga diri ibu dalam pemberian ASI eksklusif, seperti membimbing dan mendampingi ibu untuk terus memberikan ASI eksklusif meskipun mereka bekerja. Dukungan keluarga besar dalam meningkatkan harga diri juga mempengaruhi ibu menyusui. Semakin baik proses membimbing dan mendampingi ibu selama periode menyusui eksklusif, semakin tinggi harga diri mereka dalam perilaku menyusui eksklusif. Harga diri (self-esteem) yang baik akan membentuk kepercayaan diri dalam menyusui (breastfeeding self-efficacy) yang baik pula dan memperpanjang durasi menyusui (Al-Kandari and Ahmed, 2018; Kamalifard, dkk., 2019). Penelitian sebelumnya mengungkapkan bahwa kepercayaan diri ibu dalam menyusui yang baik dapat meningkatkan kesuksesan dalam ASI eksklusif (De Roza, dkk., 2019).

Semua indikator dukungan pada penelitian ini menunjukkan kategori cukup, termasuk indikator dukungan emosional. Dukungan emosional dapat diwujudkan dengan nenek sepenuhnya mendengarkan keluhan ibu selama menyusui dan memotivasi ibu untuk memberikan ASI untuk kepentingan cucunya, meskipun tidak menyusui eksklusif. Oleh karena itu, dukungan emosional keluarga sangat diperlukan. Penelitian ini mendukung penelitian sebelumnya, bahwa ibu primipara dalam keluarga yang kurang memberikan dukungan emosional, berisiko tinggi tidak memberikan ASI eksklusif daripada keluarga dengan dukungan emosional yang baik (Larasati, dkk., 2016). Meskipun terdapat responden menerima dukungan emosional yang baik, namun memilih tetap tidak memberikan ASI eksklusif.

\section{Kesimpulan}

Dukungan nenek telah memainkan peran penting dalam keberhasilan pemberian ASI eksklusif bagi ibu yang bekerja. Dukungan yang tidak memadai membuat ibu memberikan ASI non-eksklusif. Rekomendasi penelitian selanjutnya adalah bantuan menyusui oleh petugas kesehatan harus memberdayakan keluarga, terutama nenek, dan menawarkan program edukasi yang lebih menarik.

\section{Ucapan Terima Kasih}

Ucapan terimakasih kami sampaikan kepada Fakultas Kedokteran Universitas Brawijaya yang telah mendanai penelitian ini, juga kepada enumerator: Tim Murni, Dyah Ekafaraviqa Ayu Sekarputeri, dan Adilia Rimbiani.

\section{Referensi}

Al-Kandari, Y., \& Ahmed, R. A. (2018). Social, psychological and demographic variables related to breastfeeding among Kuwaiti mothers. Eastern Mediterranean Health Journal = La Revue De Sante De La Mediterranee Orientale = Al-Majallah AlSihhiyah Li-Sharq Al-Mutawassit, 24(7), 624-630.

https://doi.org/10.26719/2018.24.7.624

Chang, P.-C., Li, S.-F., Yang, H.-Y., Wang, L.-C., Weng, C.-Y., Chen, K.-F., Chen, W., \& Fan, S.Y. (2019). Factors associated with cessation of exclusive breastfeeding at 1 and 2 months postpartum in Taiwan. International Breastfeeding Journal, 14, 18. https://doi.org/10.1186/s13006-0190213-1

Dahlan, A., Mubin, F., \& Mustika, D. N. (2013). Hubungan Status Pekerjaan Dengan Pemberian Asi Eksklusif Di Kelurahan Palebon Kecamatan Pedurungan Kota Semarang. Jurnal Kebidanan, 2(2), 56-60. 
https://doi.org/10.26714/jk.2.2.2013.5660

De Roza, J. G., Fong, M. K., Ang, B. L., Sadon, R. B., Koh, E. Y. L., \& Teo, S. S. H. (2019). Exclusive breastfeeding, breastfeeding selfefficacy and perception of milk supply among mothers in Singapore: A longitudinal study. Midwifery, 79, 102532. https://doi.org/10.1016/j.midw.2019.102 532

Dinas Kesehatan (Dinkes) Kota Malang. (2016). Profil Kesehatan Kota Malang 2016. Retrieved January 18, 2021, from https://www.kemkes.go.id/resources/do wnload/profil/PROFIL_KAB_KOTA_2016/ 3573_Jatim_Kota_Malang_2016.pdf

Ferreira, T. D. M., Piccioni, L. D., Queiroz, P. H. B., Silva, E. M., \& Vale, I. N. do. (2018). Influence of grandmothers on exclusive breastfeeding: Cross-sectional study. Einstein (Sao Paulo, Brazil), 16(4), eA04293.

https://doi.org/10.31744/einstein_journa l/2018A04293

Kamalifard, M., Mirghafourvand, M., Ranjbar, F., Sharajabad, F. A., \& Gordani, N. (2019). Relationship of Breastfeeding Self-Efficacy with Self-Esteem and General Health in Breastfeeding Mothers Referred to Health Centers of Falavarjan City-Iran, 2015. Community Mental Health Journal, 55(6), 1057-1063.

https://doi.org/10.1007/s10597-01900408-6

Karmacharya, C., Cunningham, K., Choufani, J., \& Kadiyala, S. (2017). Grandmothers' knowledge positively influences maternal knowledge and infant and young child feeding practices. Public Health Nutrition, 20(12),

2114-2123. https://doi.org/10.1017/S136898001700 0969

Ke, J., Ouyang, Y.-Q., \& Redding, S. R. (2018). Family-Centered Breastfeeding Education to Promote Primiparas' Exclusive Breastfeeding in China. Journal of Human Lactation: Official Journal of International Lactation Consultant Association, 34(2), 365-378.

https://doi.org/10.1177/0890334417737 293
Kohan, S., Keshvari, M., Mohammadi, F., \& Heidari, Z. (2019). Designing and Evaluating an Empowering Program for Breastfeeding: A Mixed-Methods Study. Archives of Iranian Medicine, 22(8), 443452.

Larasati, T., Pangestuti, D. R., \& Rahfiludin, M. Z. (2016). Hubungan Dukungan Suami Dengan Praktik Pemberian Asi Eksklusif Pada Ibu Primipara (Studi di Wilayah Kerja Puskesmas Jebed Kabupaten Pemalang). Jurnal Kesehatan Masyarakat (Undip), 4(4), 594-608.

McQueen, K., Sieswerda, L. E., Montelpare, W., \& Dennis, C.-L. (2015). Prevalence and factors affecting breastfeeding among Aboriginal women in Northwestern Ontario. Journal of Obstetric, Gynecologic, and Neonatal Nursing: JOGNN, 44(1), 51$68 . \quad$ https://doi.org/10.1111/15526909.12526

Negin, J., Coffman, J., Vizintin, P., \& RaynesGreenow, C. (2016). The Influence of Grandmothers on Breastfeeding Rates: A Systematic Review. BMC Pregnancy and Childbirth, 16(1), 91. https://doi.org/10.1186/s12884-0160880-5

Oktalina, O., Muniroh, L., \& Adiningsih, S. (2015). Hubungan Dukungan Suami dan Dukungan Keluarga dengan Pemberian ASI Eksklusif pada Ibu Anggota Kelompok Pendukung ASI (KP-ASI). Media Gizi Indonesia, 10(1), 64-70. https://doi.org/10.20473/mgi.v10i1.6470

Rahmawati, N. I. (2016). Dukungan Informasional Keluarga Berpengaruh dalam Pemberian ASI Eksklusif di Desa Timbulharjo Sewon Bantul. Jurnal Ners Dan Kebidanan Indonesia, 4(2), 75-78. https://doi.org/10.21927/jnki.2016.4(2). 75-78

Ramadani, M. (2017). Dukungan Keluarga Sebagai Faktor Dominan Keberhasilan Menyusui Eksklusif. Media Kesehatan Masyarakat Indonesia, 13(1), 34-41.

Ratnasari, D., Paramashanti, B. A., Hadi, H., Yugistyowati, A., Astiti, D., \& Nurhayati, E. (2017). Family support and exclusive breastfeeding among Yogyakarta mothers 
in employment. Asia Pacific Journal of Clinical Nutrition, 26(Suppl 1), S31-S35. https://doi.org/10.6133/apjcn.062017.s8

Scelza, B. A., \& Hinde, K. (2019). Crucial Contributions: A Biocultural Study of Grandmothering During the Perinatal Period. Human Nature (Hawthorne, N.Y.), 30(4), 371-397. https://doi.org/10.1007/s12110-01909356-2

Suryaningsih, C. (2013). Pengaruh Pendidikan Kesehatan terhadap Pengetahuan Ibu Post Partum Tentang ASI Eksklusif. Jurnal Keperawatan Soedirman, 8(2), Article 2. https://doi.org/10.20884/1.jks.2013.8.2.4 71

Susiloretni, K. A., Hadi, H., Prabandari, Y. S., Soenarto, Y. S., \& Wilopo, S. A. (2015). What works to improve duration of exclusive breastfeeding: Lessons from the exclusive breastfeeding promotion program in rural Indonesia. Maternal and Child Health Journal, 19(7), 1515-1525. https://doi.org/10.1007/s10995-0141656-z

Trisnawati, E., \& Widyastutik, O. (2018). Kegagalan ASI Eksklusif: Manajemen Laktasi Dan Dukungan Keluarga. Jurnal Formil (Forum Ilmiah) Kesmas Respati, 3(2), 89-99.

https://doi.org/10.35842/formil.v3i2.177

Zhu, X., Liu, L., \& Wang, Y. (2016). Utilizing a Newly Designed Scale for Evaluating Family Support and Its Association with Exclusive Breastfeeding. Breastfeeding Medicine: The Official Journal of the Academy of Breastfeeding Medicine, 11, 526-531. https://doi.org/10.1089/bfm.2016.0090 